\title{
Variant insertion of coracobrachialis muscle-morphological significance, embryological basis and clinical importance
}

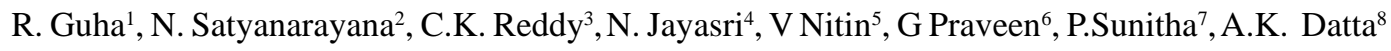 \\ ${ }^{1}$ Professor in Anatomy, ${ }^{8}$ Professor \& HOD ${ }^{2,5,6}$ Lecturer in Anatomy, College of Medical Sciences, Bharatpur, Chitwan District \\ Nepal, ${ }^{3}$ Associate Professor in Anatomy, PIMS, Kariminager,India, ${ }^{4}$ Professor\&HOD, Dept of Anatomy, CAIMS, Karimnagar, \\ ${ }^{7}$ Lecturer in Physiology.
}

\begin{abstract}
The coracobrachialis muscle in the arm is morphologically the sole representative of adductor group muscle in the arm, but such function during the process of evolution became insignificant in man. It is more important morphologically than functionally. Variant insertion of the coracobrachialis muscle was found during routine dissection of an adult male cadaver in the Department of Anatomy, College of Medical Sciences, and Bharatpur, Nepal. Normally the coracobrachialis muscle is inserted into the middle of the medial border of the humerus. In the present case an additional slender tendon passed inferiorly, crossing anterior to the median nerve and brachial artery, before attaching to the medial epicondyle of the humerus. Most of the proximal part of the tendon gave rise to an aponeurotic expansion that inserted into the distal medial border of the humerus. The tendinous insertion and aponeurotic expansion may represent a variant of the coracobrachialis longus (Wood's) muscle and the internal brachial ligament or the ligament of Struthers. The ulnar nerve was found to be traversing below the aponeurotic expansion. This type of anomalous insertion of coracobrachialis muscle may lead to compression of median nerve, brachial artery and ulnar nerve.
\end{abstract}

Key words: Coracobrachialis muscle, ligament of Struthers, median nerve, brachial artery, ulnar nerve.

\section{Case report}

During routine dissection of an adult male cadaver in the Department of Anatomy, College of Medical Sciences, Bharathpur, Nepal, normal origin and unusual insertion of coracobrachialis muscle was observed in the left arm. The coracobrachialis muscle was found to arise from the apex of coracoid process together with the tendon of short head of biceps brachii. Major part of the muscle was inserted into the medial border of the humerus near middle of the shaft. However, a superficial part of the muscle was found to give rise to an additional slender tendon. The tendon passed inferiorly, crossing anterior

Correspondence: Dr. R. Guha

E-mail:.guharanjit@yahoo.co.in

to the median nerve and brachial artery, to be attached into the medial epicondyle of the humerus (Fig. 1). The proximal part of the tendon formed an aponeurotic expansion that was inserted into the medial intermuscular septum and the distal part of the medial border of the shaft of the humerus. The median nerve 
R. Guha et al, Variant insertion of coracobrachialis muscle-

and brachial artery passed through an opening bounded anteriorly by the additional slender tendon (Fig.2) and posteriorly by the aponeurotic expansion and the usual humeral insertion of the coracobrachialis muscle. The ulnar nerve was noted to be passing below the aponeurotic expansion.

The relation of the median nerve and brachial artery were seen to be normal, median nerve crossing the brachial artery from its superficial aspect in the middle of the arm from lateral to medial side. The musculocutaneous nerve was seen to be arising normally from the lateral cord of brachial plexus opposite the lower border of pectoralis minor and piercing the coracobrachialis muscle.

Further course of the median nerve, brachial artery and musculocutaneous nerve and their branches was found to be normal. Disposition of other structures of the left arm was also found to be normal. The right arm was also dissected meticulously but revealed normal arrangement of the lower attachment of coracobrachialis muscle and normal disposition of other structures of arm.

\section{Discussion}

Usually coracobrachialis muscle arises from the apex of the coracoid process, together with the tendon of the short head of the biceps, and also by muscular fibres from the proximal $10 \mathrm{~cm}$ of this tendon. It ends on an impression, $3-5 \mathrm{~cm}$ in length, midway along the medial border of the humeral shaft between the attachments of triceps and brachialis. The muscle forms an inconspicuous rounded ridge on the upper medial side of the $\operatorname{arm}^{1}$.

The coracobrachialis muscle is more important morphologically than functionally. The coracobrachialis muscle in the arm is morphologically the sole representative of adductor group muscle in the arm, but such function during the process of evolution became insignificant in man. Three distinct parts of the coracobrachialis muscle are described in amphibians, reptiles, and monotremes :1) coracobrachialis brevis (profundus), which is inserted into the humerus superior to tendon of latissimus dorsi, 2) coracobrachialis medius (proprius), which is inserted into the humerus inferior to tendon of latissimus dorsi, and 3) coracobrachialis longus (superficialis) or Wood's muscle, which extends inferiorly on the shaft of humerus bridging the median nerve and brachial artery $2,3,4,5$. Some apes and prosimians have coracobrachialis muscle composed of two parts, which is equivalent to coracobrachialis brevis. The coracobrachialis in man is formed of one muscular part that probably represent the persistence of coracobrachialis medius of lower animals or the fusion of two heads of that muscle are observed in apes and prosimians, trapping the musculocutaneous nerve between them. ${ }^{6,7,8}$

The tendinous insertion in the present case may represent a variant of coracobrachialis longus muscle. Wood (1867) described it as extending from the coracoid process of the scapula to the upper part of medial supracondylar ridge ${ }^{2}$. It may be partly inserted into a ligamentous band that extends inferiorly as far as the medial epicondyle and covers the ulnar nerve, or it may insert on an anomalous supracondylar process (supratrochlear spur), if present. ${ }^{9}$

The aponeurotic insertion of the coracobrachialis muscle described in this report may be comparable to the internal brachial ligament described in the literature. Different descriptions have been given by different authors as to its anatomy ${ }^{2,5,10}$. 
The ligament of Struthers was first described as a fibrous band extending from the supracondylar (supracondyloid) process or spur on the anteromedial aspect of the humerus downwards to the medial epicondyle ${ }^{10}$ This description was later supported by various authors 9,11,12,13,14 The ligament of Struthers has been found to occurs in $<2 \%$ of humans and has rarely been associated with symptoms ${ }^{15,16}$ Terry (1921) carried out manual examination of 1,000 patients and found a palpable supracondylar process in $0.7 \%$ of them ${ }^{17}$. At times the supracondylar process forms an arch that is homologous to the bony arch observed in the inferior part of the humerus in cats and some monkeys ${ }^{11,12,18}$ In the cat, this opening is formed completely by an arch of bone leaving and again joining the lower part of medial aspect of the shaft of the humerus ${ }^{10}$.Wood (1867) reported also that when the internal brachial ligament is well developed, it may pass entirely superficial to and across the brachial vessels and median nerve, forming an aponerotic opening for them which is known as the supracondylar opening ${ }^{2}$. Occasionally a fibrous strip usually passes from the tendon, near its humeral insertion, to the long head of triceps; occasionally muscular, it is homologue of the dorso-epitrochlearis brachii of apes ${ }^{1}$.

A hook shaped supracondylar process, 2 to $20 \mathrm{~mm}$ in length, occasionally projects from the anteromedial surface of the shaft, proximal to the medial epicondyle. It curves distally and forwards, its apex being connected to the medial border, proximal to the epicondyle, by a fibrous band, to which part of pronator teres is attached. The foramen so formed usually encloses the median nerve and brachial artery, but sometime only nerve or perhaps nerve plus the ulnar artery in high division of the brachial artery. A groove for the artery and nerve usually exits behind the process.
It is homologue of the entepicondylar foramen of many animals and many protect the nerve and artery from compression by muscle ${ }^{1}$.

The origin of morphologic variation of the coracobrachialis may be explained on the basis of the embryogenesis of the muscles of the arm. The intrinsic muscles of the upper limb differentiate in situ from the limb bud mesenchyme of lateral plate mesoderm. At a certain stage of development, the muscle primordia within the different layers of the arm fuse to form a single muscle mass, there after, some muscle primordial disappear through cell death ${ }^{19,20}$. Failure of muscle primordial to disappear during embryologic development may account for the presence of the accessory insertion of coracobrachialis muscle reported in this case.

Several cases of median nerve entrapment have been attributed to the presence of ligament of Struthers. The ligament of Struthers complex is well known to cause neurovascular compression syndromes ${ }^{21,22,23,24}$. It typically affects the median nerve and the brachial artery, or both, but several cases of ulnar nerve compression exist as well ${ }^{25}$ As high median nerve entrapment being uncommon and having an elusive diagnosis, the presence of ligament of Struthers should be kept in mind as a possible cause of median nerve and brachial artery compression. It may lead to ischaemic contraction and wasting of flexor group of muscles of forearm.

\section{References}

1. Williams PL, Bannister LH, Berry MM, Collins P, Dyson M, Dussek JE et al - Gray's Anatomy. $38^{\text {th }}$ ed. London Churchill Livingstone, 1999; p 842. 626, 837. 
R. Guha et al, Variant insertion of coracobrachialis muscle-

2. Wood J. On human muscular variations and their relation to comparative anatomy. J Anat Physiol 1867; 1:44-59.

3. Sonntag C. On the anatomy, physiology, and pathology of the chimpanzee. Proc zool soc 1923; 22:323-63.

4. Sonntag CF. On the anatomy, physiology, and pathology of the chimpanzee. Proc zool soc 1924; 224:329-80.

5. Howell AB, Straus WL. The brachial flexor muscles in primates. Proc US Natl Museum.1932; 80:1-31.

6. Sommer A. Das Muskelsystem des Gorilla. Jenaische Zeitschrift fu“ $r$ Natur wissenschaft 1906; 42:181-308.

7. Koizumi M.A morphological study on the Coracobrachialis muscle. Kaibogaku Zasshi 1989; 64:18 -35.

8. McMinn RMH. editor. Last's anatomy: regional and applied. $8^{\text {th }}$ ed. Edinburgh: Churchill Livingstone. 1990; 79.

9. Bergman RA, Thompson SA, Afifi AK, Saadeh FA. Compendium of human anatomic variation. BaltimoreMunich: Urban \& Schwarzenberg 1988; 277.

10. Struthers J. On some points in the abnormal anatomy of the arm. Brfor Med Chir Rev 1854; 14:224 -36.

11. Witt CM. The supracondyloid process of the humerus. J Missouri Med Assn 1950; 47:445-46

12. Kessel L, Rang M. Supracondylar spur of the humerus. J Bone Joint Surg 1966; 48(B):765-69.

13. Hollinshead WH. Anatomy for surgeons. Vol. 3. $3^{\text {rd }}$ ed. Philadelphia: Harper \& Row. 1982; 341-69.

14. Gunther SF, DiPasquale D, Martin R. Struthers' ligament and associated median nerve variations in a cadaveric specimen. Yale J Biol Med1993; 66:203-08.

15. Tountas CP, Bergman RA. Anatomic variations of the upper extremity. New York: Churchill Livingstone. 1993; 94-95.
16. Pec'ina MM, Krmpotic'-Nemanic' J, Markiewitz AD. Tunnel syndromes. Boca Raton, FL: CRC Press Inc. 1991; 51-53.

17. Terry RJ. A study of the supracondyloid process in the living. Am J Phys Anthrop 1921; 4:129-39.

18. Marquis JW, Bruwer AJ, Keith HM. Supracondyloid process of the humerus. Proc Staff Meet Mayo Clinic1957; 32:691-97.

19. Ciha'kR. Ontogenesis of the skeleton and intrinsic muscles of the human hand and foot. Adv Anat Embryol Cell Bioll. 1972; 46: 1-194.

20. Grim M. Ultra structure of the ulnar portion of the contrahent muscle layer in the embryonic human hand. Folia Morphol 1972; 20:113-15.

21. Lund HJ. Fracture of the supracondyloid process of the humerus: a case report. J Bone Joint Surg 1930; 12: 925-28.

22. Smith RV, Fisher RG. Struthers ligament: a source of median nerve compression above the elbow. J Neurosurg 1973; 38:778-79.

23. Al-Qattan MM, Husband JB. Median nerve compression by the supracondylar process: a case report. J Hand Surg Br 1991; 16B:101-03.

24. Ivins GK. Supracondylar process syndrome: a case report.J Hand Surg 1996; 21:279-81.

25. Mustafa M, El-Naggar and Samar Al-saggif. Variant of coracobrachialis Muscle with a tunnel for the median nerve and brachial artery: a case report. Clinical Anat 2004; 17:139-43. 


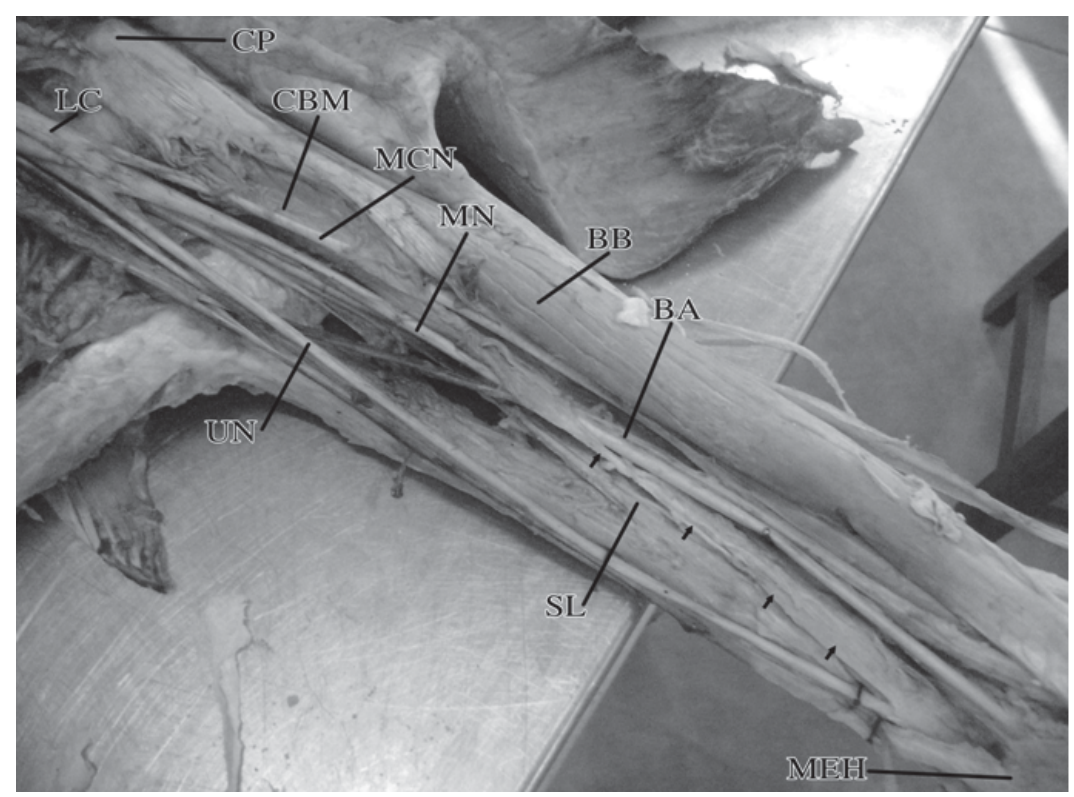

Fig.1. The left upper arm showing an additional insertion of the Coracobrachialis muscle in the form of a slender tendon arising from the superficial part of the muscle, the tendon passing inferiorly crossing anterior to median nerve and brachial artery and getting attached to medial epicondyle of humerus; the proximal part of the tendon giving off an aponeurotic expansion covering the ulnar nerve. $\mathrm{CP}=$ Coracoid process, $\mathrm{CBM}=\mathrm{Coracobrachialis}$ muscle, $\mathrm{SL}=$ Struthers ligament, $\mathrm{LC}=$ Lateral cord, $\mathrm{MC}=$ Medial cord, $\mathrm{MCN}=$ Musculocutaneous nerve, $\mathrm{MN}=$ Median nerve, $\mathrm{UN}=$ Ulnar nerve, $\mathrm{BA}=$ Brachial artery, $\mathrm{BB}=$ Biceps brachii, $\mathrm{MEH}=$. Medial epicondyle of humerus.

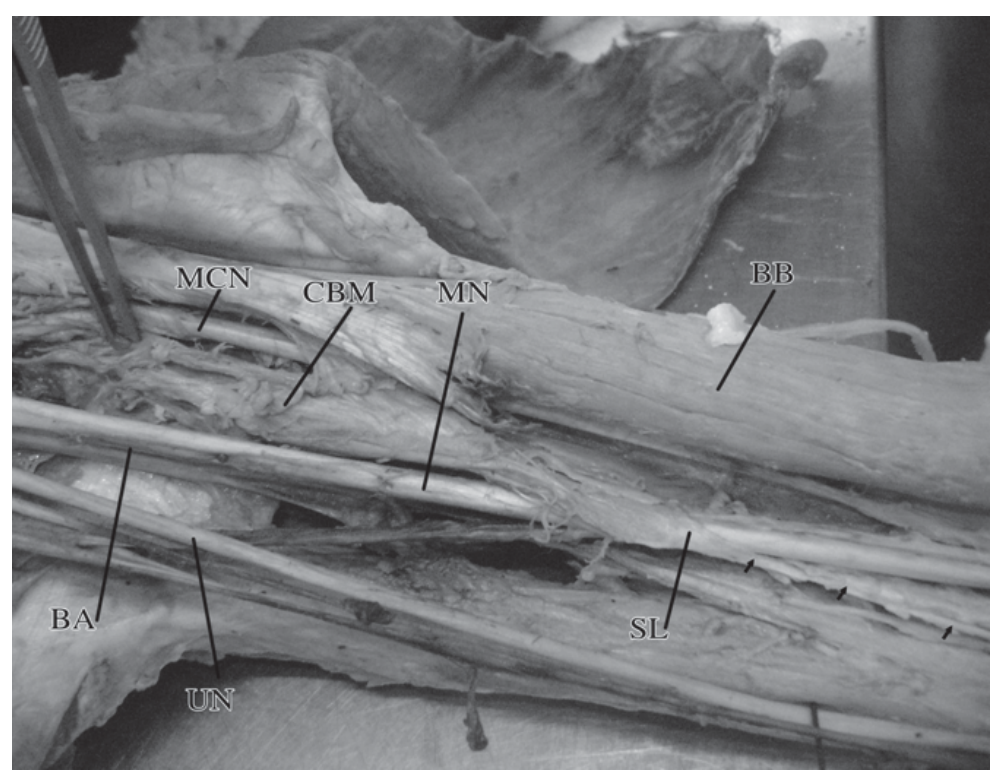

Fig.2. Showing the passage of tendon (Struthers ligament) over the median nerve and brachial artery. $\mathrm{CBM}=$ Coracobrachialis muscle, $\mathrm{SL}=$ Struthers ligament, $\mathrm{MCN}=$ Musculocutaneous nerve, $\mathrm{MN}=$ Median nerve, $\mathrm{UN}=\mathrm{Ulnar}$ nerve, $\mathrm{BA}=\mathrm{Brachial}$ artery, $\mathrm{BB}=$ Biceps brachii. 